\title{
Rural households at risk of malaria did not own sufficient insecticide treated nets at Dabat HDSS site: evidence from a cross sectional re-census
}

Kindie Fentahun Muchie ${ }^{1,4^{*}}$ (D), Kassahun Alemu ${ }^{1,4}$, Amare Tariku ${ }^{2,4}$, Adino Tesfahun Tsegaye ${ }^{1,4}$, Solomon Mekonnen Abebe ${ }^{2,4}$, Mezgebu Yitayal ${ }^{3,4}$, Tadesse Awoke ${ }^{1,4}$ and Gashaw Andargie Biks $s^{3,4}$

\begin{abstract}
Background: Malaria is the leading cause of disease burden across the world, especially in African countries. Ethiopia has designed a five year (2011-2015) plan to cover 100\% of the households in malarious areas with one insecticide treated net (ITN) for every two persons, and to raise consistent ITN utilization to at least $80 \%$. However, evidence on ownership of ITN among malarious rural households in northwest Ethiopia is quite limited. Hence, the present study aimed at assessing ownership of ITN and associated factors among rural households at risk of malaria at Dabat Health and Demographic Surveillance System site, northwest Ethiopia.

Methods: A cross sectional re-census was carried out in Dabat Health and Demographic Surveillance System site during peak malaria seasons from October to December, 2014. Data for 15,088 households at Dabat Health and Demographic Surveillance System site were used for the analysis. Descriptive measures and binary logistic regression were carried out.

Results: Among those who owned at least one ITN, 53.4\% were living at an altitude $>2500 \mathrm{~m}$ above sea level. However, out of households living at an altitude $<2000 \mathrm{~m}$ above sea level, 15.8\% (95\% Cl 14.4\%, 17.3\%) owned ITN at an average of $4.3 \pm 2.1$ persons per ITN. Of these, $69.5 \%(95 \% \mathrm{Cl} 64.7 \%, 74.1 \%)$ used the ITN. Among utilizing households at malarious areas, $23.7 \%$ prioritized pregnant women and $31.4 \%$ children to use ITN. The availability of radio receiver/mobile (AOR 1.60, $95 \% \mathrm{Cl} 1.08,2.35$ ) and secondary/above educational status of household member (AOR 1.54,95\%Cl 1.19, 2.04) were predictors of ownership of ITN.

Conclusion: Rural households at risk of malaria did not own a sufficient number of ITN though the utilization is promising. Moreover, prioritizing children and pregnant women to sleep under ITN remains public health problems. Programmers, partners and implementers should consider tailored intervention strategy stratified by altitude in distributing ITN. ITN distribution should also be accompanied by using exhaustive promotion strategies that consider people without access to any source of information, and educating households to prioritize pregnant and under five children to sleep under ITN.
\end{abstract}

Keywords: Altitude, Determinants, ITN, Ownership, Utilization, Dabat, HDSS, Northwest Ethiopia

\footnotetext{
*Correspondence: mkindief@gmail.com

'Department of Epidemiology and Biostatistics, Institute of Public Health,

College of Medicine and Health Sciences, University of Gondar, Gondar,

Ethiopia

${ }^{4}$ Dabat Research Centre Health and Demographic Surveillance System,

Institute of Public Health, College of Medicine and Health Sciences,

University of Gondar, Gondar, Ethiopia

Full list of author information is available at the end of the article
} 


\section{Background}

Malaria is the leading cause of disease burden across the world, especially in African countries. Globally, there were 214 million new cases of malaria in 2015 [1], of which $88 \%$ was from the African region. In the same year, there were an estimated 438,000 malaria deaths worldwide. But most of these deaths (90\%) occurred in the African region [1]. Malaria is a major public health problem in Ethiopia where it is among the ten top leading causes of morbidity and mortality in children under-5 years $[2,3]$.

Malaria transmission exhibits a seasonal pattern in Ethiopia. The major transmission season in the country is from September to December, following the main rainy season (June/July to September), and between May and July following the end of the dry season [4]. The transmission also varies with altitude and rainfall [4-6]. In the country, areas below $2000 \mathrm{~m}$ above sea level (masl) were considered malarious [7]. However, malaria prevalence among individuals living at areas $>2000$ and $>=2500$ masl were zero [8]. Accordingly, about $75 \%$ of the areas in the country are malarious and targeted to receive key control intervention [9].

Vector control is the main way to prevent and reduce malaria transmission. Insecticide-treated nets (ITNs) are effective control mechanism in a wide range of circumstances [1]. Ethiopia has designed a five year (2011-2015) plan to cover $100 \%$ of households ( $\mathrm{HHs}$ ) in malarious areas with one ITN for every two persons, and to reach at least $80 \%$ consistent ITN utilization to fight the vector [4].

ITNs as a tool for malaria control can present challenges, such as coverage and proper use [10]. Ownership and utilization of ITNs are two important indicators of monitoring progress towards the target to control the vector [11]. Ownership is important to assess the effectiveness of the distribution channels of ITNs and suggest program modifications where there are lapses [11]. However, utilization is an indicator that generates the epidemiological impact [12].

Periodic household $(\mathrm{HH})$ surveys were recommended by the World Health Organization (WHO) to assess whether people at risk receive sufficient ITNs and whether there is proper use of ITNs [13]. Some evidences showed that the existence of rapid increases in ITN coverage in some of the poorest countries in Africa, but coverage remains low in large populations at risk [14]. Different studies conducted in the country and parts of the world have shown that there were a lot of ups and downs regarding ITNs ownership and utilization at HH levels [15-22]. Besides, though designing tailored intervention for the stratification by altitude within areas in Ethiopia is recommended [8], studies assessing ITN distribution by altitude were limited in the study area.

Evidences extracted from different studies have shown that ownership and utilization status of ITNs were affected by different factors including geographical, individual, $\mathrm{HH}$, and environmental. Some of them were residence, literacy level of $\mathrm{HH}$ members, awareness about ITNs, geographical settlements of $\mathrm{HHs}$, awareness on malaria prevention, sex of $\mathrm{HH}$ head, $\mathrm{HH}$ head income, availability of radio receiver, duration since ITNs were received by the $\mathrm{HH}$, family size of the $\mathrm{HH}$, and occupational status of head of the $\mathrm{HH}[15,17-27]$. Most studies currently emphasized on the factors affecting utilization of ITN [17, 20, 22]. However, there is an evidence in Ethiopia showing low ownership of ITNs while utilization is promising [28]. Besides, in countries, including Ethiopia, with limited resource and varying malaria transmission pattern it might be important to prioritize ownership of ITN and its factors.

Evidence about ownership of sufficient ITNs among $\mathrm{HH}$ in rural malarious areas, northwest Ethiopian is quite limited. Hence, the present study aimed at assessing ITN ownership and associated factors among rural HHs at risk of malaria at Dabat Health and Demographic Surveillance System (HDSS) site, northwest Ethiopia. The finding of this analysis would help to evaluate the current malaria control activities by ITN in the study setup. If properly utilized, this information will urge the decision makers to strengthen malaria control interventions effectively and efficiently.

\section{Methods \\ Study setting}

The Dabat HDSS site is located in a rural part of the Amhara Regional State in northwest Ethiopia (Fig. 1). The altitude ranges from about 1000 to 3000 masl. Dabat district was initially selected purposively as a surveillance site for its unique three climatic conditions, namely Dega (highland and cold), Woina-dega (midland and temperate) and Kolla (lowland and hot). The choice was made with the assumption that there would be differences in morbidity and mortality in the different climatic areas. Accordingly, thirteen kebeles (nine rural and four urban) were selected after stratification of the kebeles by climatic zone. "Kebeles" are the smallest administrative units in towns and cities in Ethiopia. Dabat HDSS is a full member of the International Network of Demographic Evaluation of Populations and Their Health (INDEPTH). The detailed data collection system, data quality control, the database, and the study setting of Dabat HDSS are described at the website of the University of Gondar [29].

\section{Study design and population}

Since the establishment of the Dabat HDSS site in November 1996, information on vital events has been being collected every six months and verbal autopsy (VA) as soon as the events happened. The cross sectional re-census was carried out at $\mathrm{HH}$ levels of the site in 


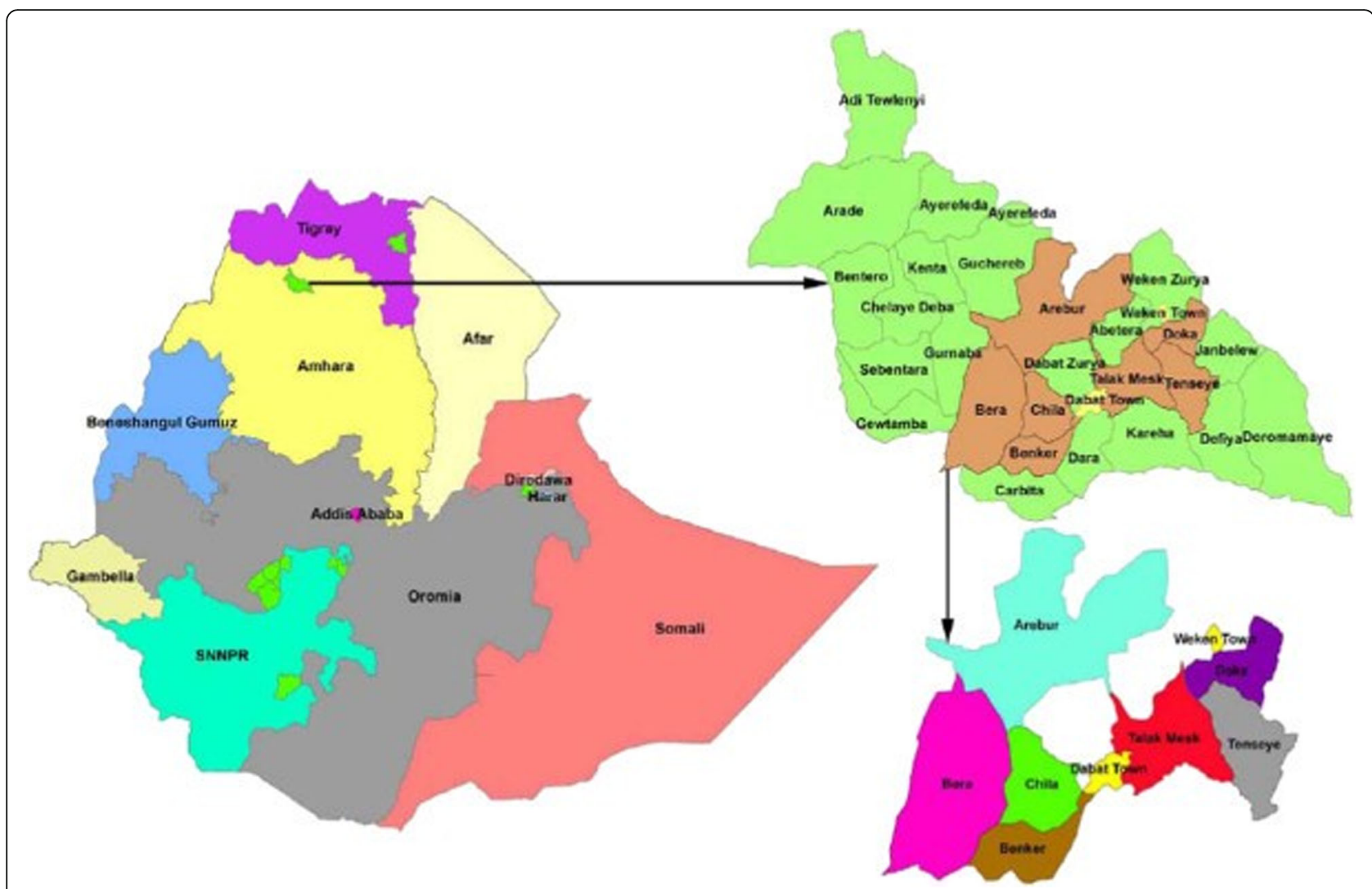

Fig. 1 Dabat Health and Demographic Surveillance System Site in northwest Ethiopia. Kebeles in the site showed by different colors

the peak malaria seasons of October to December 2014, was used for this study.

\section{Methods of data collection}

All HHs in the nine rural and four urban kebeles were covered during the data collection period. This was done using a standardized WHO questionnaire that elicits general information about HHs, the demographic characteristics of $\mathrm{HH}$ members, housing and environmental conditions in the site [30]. For this analysis, the $\mathrm{HH}$ questionnaire which was adapted and translated to Amharic, the National language was used. Furthermore, the respondents were asked about presence, number, and condition of mosquito nets (verified by observation for hole size referencing 'torch battery' size D cell, diameter $33 \mathrm{~mm}$, for hole size reference); and nets used the previous night. Altitude and location of each $\mathrm{HH}$ were recorded using the Global Positioning System (GPS).

\section{Variables of the study}

The outcome variable considered in this study was ownership of ITNs at a HH level. In this study, all insecticidetreated nets, whether long lasting or retreated are referred to as ITNs. Ownership of ITN was defined as "whether a $\mathrm{HH}$ own at least one functional ITN". With respect to ITNs utilization, a HH was taken as "utilized" if the ITNs were used in the night preceding the survey among HHs who owned them.

\section{Data management and analysis}

Data were entered into the database, using the software household registration system (HRS) version 2.1, and exported to Stata 14.0 for further analysis. Households

Table 1 Count (\%) of households that own ITN by altitude at Dabat HDSS site, northwest Ethiopia, Oct. to Dec. 2014

\begin{tabular}{|c|c|c|c|c|c|c|}
\hline & & \multicolumn{4}{|c|}{ Altitude (in meters above sea level) } & \multirow[b]{2}{*}{ Total } \\
\hline & & $<2000$ & $2000-2299$ & $2300-2499$ & $>2500$ & \\
\hline \multirow[t]{2}{*}{ Own ITN } & Yes & $396(22.5)$ & $83(4.7)$ & $340(19.4)$ & 938(53.4) & $1757(11.6)$ \\
\hline & No & 2106(15.8) & $265(2.0)$ & 1497(11.2) & $9463(71.0)$ & $13,331(88.4)$ \\
\hline Total & & 2502(16.6) & $348(2.3)$ & $1837(12.2)$ & $10,401(68.9)$ & 15,088 \\
\hline
\end{tabular}


were divided into socioeconomic quantiles based on their scores. In order to capture wealth differences between urban and rural residences, the Principal Component Analysis (PCA) scores were generated for the two areas (urban and rural $\mathrm{HH}$ wealth indices) separately. The dimension of the PCA explaining 69\% was taken as the score for the HH. Finally, the common factor scores were summed and ranked into lowest, lower, middle, higher, and highest. Data from the 15,088 HHs living in the Dabat HDSS site were used for exploring the distribution of ITN ownership by altitude., Out of $2502 \mathrm{HHs}$ living in malarious areas (altitude <2000 masl), 2495 with complete data (associated with ITN ownership) were used for further multivariable analysis.

Descriptive measures were used to present characteristics of the HHs in the study area. Bi-variable binary logistic regression analysis was done to determine the association of the response variable and explanatory factors considered in this study. Significant variables $(p$-value $<0.25)$ observed in bi-variable analysis were subsequently included in multivariable binary logistic regression analysis. Finally, results were reported as statistically significant whenever $p$-values were less than 0.05. Adjusted odds ratio (AOR) was used to report the strength of association between the outcome and explanatory variables.

\section{Results}

Distribution of $\mathrm{HH}$ and ownership of ITN by altitude at Dabat HDSS site

In Dabat HDSS site the majority of $\mathrm{HHs}, 68.9 \%$, were living at an altitude of $>2500$ masl, whereas $16.6 \%$ were at an altitude of $<2000$ masl (Table 1 ).

Moreover, almost all of the HHs in Bera and Arebur kebeles lived at <2000 masl (Fig. 2). However, the majority of the HHs in Benker, Dabat town, Talak Mesk, Chila, Weken town, Doka and Tenseye kebeles lived at $>2500$ masl.

Out of the HHs in the Dabat HDSS site, $11.6 \%$ owned at least one ITN (Table 1). Out of those who owned at least one ITN, $53.4 \%, 22.5 \%, 19.4 \%$, and $4.7 \%$ lived at an altitudes of $>2500$ masl, $<2000$ masl, 2300-2500 masl, and 2000-2300 masl, respectively.

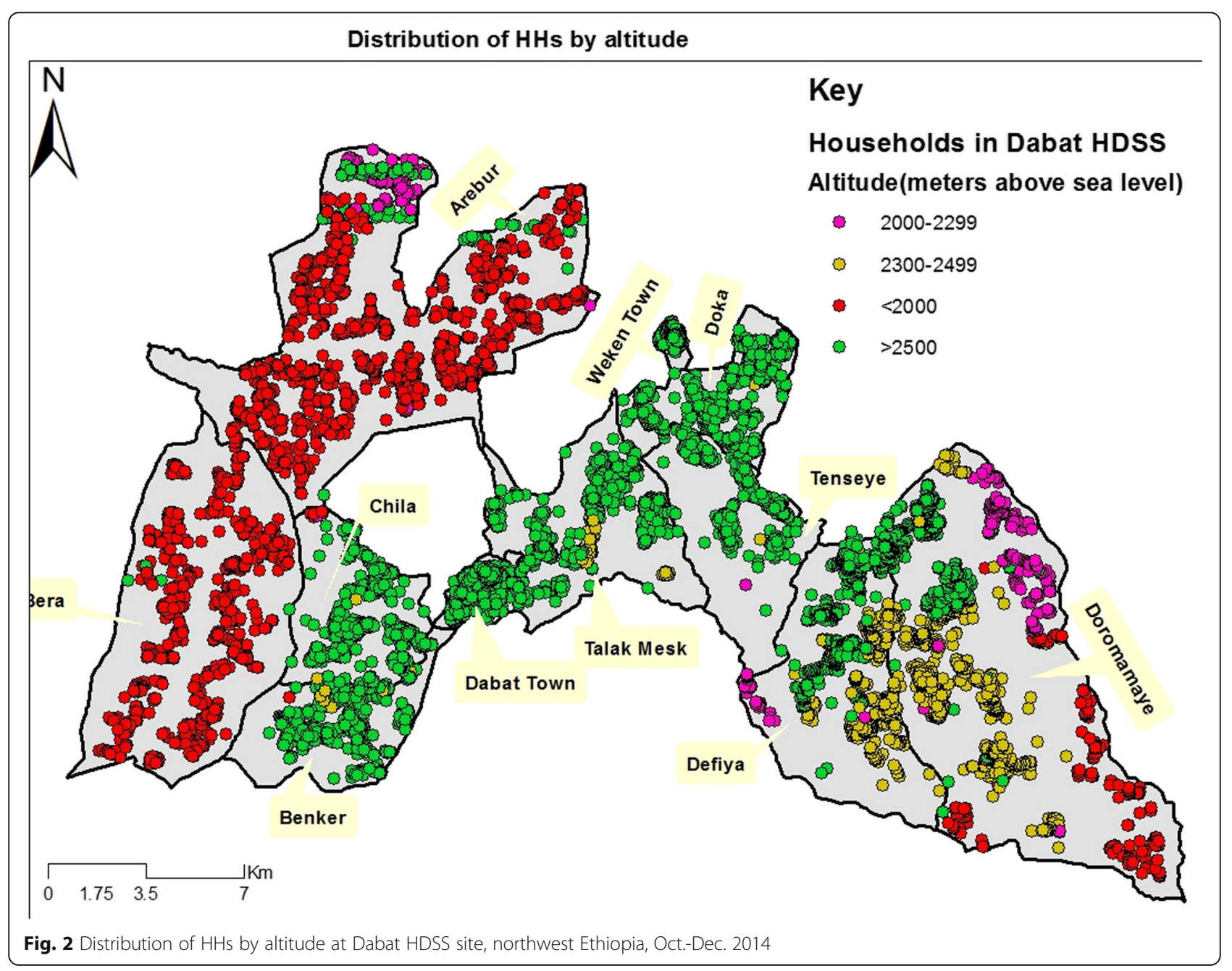


It has been observed that some HHs living at $>2500$ masl owned ITN even though a large number of those living at <2000 masl did not (Fig. 3).

\section{Socio-demographic characteristics at malarious areas of Dabat HDSS site}

Almost all, 99.9\% $\mathrm{HHs}$ at malarious areas of Dabat HDSS site were rural residents. Regarding family size, the average size was $5.1(\mathrm{~S} . \mathrm{D}=2.2)$. With respect to $\mathrm{HH}$ head characteristics, $19.5 \%$ of $\mathrm{HHs}$ were female headed, while the majority of $\mathrm{HH}$ heads, $78.2 \%$ were cohabiting and $84.6 \%$ were farmers. Of the $\mathrm{HHs}$ at the malarious areas of the Dabat HDSS site, $17.3 \%$ owned sources of information (radio receivers or mobile phones) (Table 2).

\section{Ownership and utilization of ITN at malarious areas of Dabat HDSS site}

Only $15.8 \%$ (95\%CI: $14.4 \%, 17.3 \%)$ of the $\mathrm{HHs}$ at malarious areas of Dabat HDSS site had at least one ITN with an average of $4.3(\mathrm{~S} . \mathrm{D}=2.1)$ persons per ITN. Out of these, 69.5\% (95\%CI: 64.7\%, 74.1\%) utilized the net. Of the utilizing $\mathrm{HHs}$, only $31.4 \%$ prioritized children and $23.7 \%$ pregnant women to sleep under ITNs (Table 3).

\section{Determinants of ITNs ownership at malarious areas of Dabat HDSS site}

In the bi-variable binary logistic regression analysis, variables including access to information source, maximum educational status, family size and age of $\mathrm{HHs}$ head were significantly associated at 0.25 level of significance. Consequently, all these were considered for the final model. Possession of information source and maximum educational status $\mathrm{HH}$ members were statistically significant determinants of ownership of ITN at malarious areas at the Dabat HDSS site, northwest Ethiopia, at 5\% level of significance.

$\mathrm{HH}$ members with highest educational status (secondary and above $)$ were $60 \%(\mathrm{AOR}=1.60 ; p$-value $=0.018 ; 95 \% \mathrm{CI}$ : $1.08,2.35)$ more likely to own ITNs as compared to completely uneducated $\mathrm{HH}$ members. A household possessing some source of information, either radio receiver or mobile phone was $54 \%(\mathrm{AOR}=1.54 ; \mathrm{p}$-value $=0.001 ; 95 \% \mathrm{CI}$ :

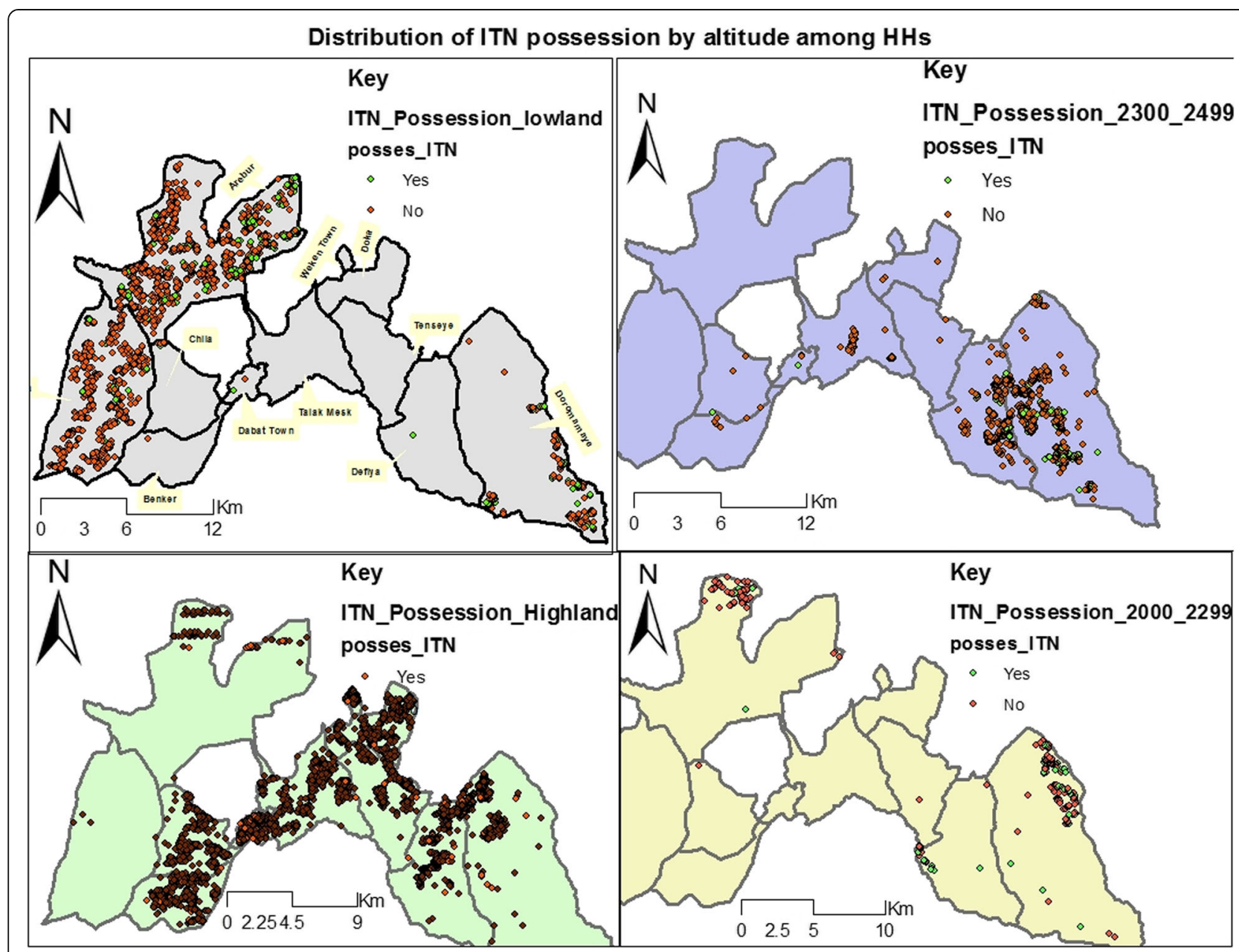

Fig. 3 Distribution of ITN ownership by altitude among HHs at Dabat HDSS site, northwest Ethiopia, Oct.- Dec. 2014 
Table 2 Household socio-demographic characteristics at malarious areas of Dabat HDSS site, northwest Ethiopia, Oct. to Dec. 2014

\begin{tabular}{|c|c|c|}
\hline Variables & Frequency & Percent \\
\hline \multicolumn{3}{|c|}{$\mathrm{HH}$ access to source information } \\
\hline No & 2063 & 82.7 \\
\hline Yes & 432 & 17.3 \\
\hline \multicolumn{3}{|l|}{ Sex of HH head } \\
\hline Female & 486 & 19.5 \\
\hline Male & 2009 & 80.5 \\
\hline \multicolumn{3}{|l|}{ Educational level in $\mathrm{HH}$} \\
\hline Un educated & 866 & 34.7 \\
\hline Primary & 1391 & 55.81 \\
\hline Secondary and above & 238 & 9.5 \\
\hline \multicolumn{3}{|l|}{ HH size } \\
\hline $1-4$ & 1034 & 41.4 \\
\hline $5+$ & 1461 & 58.6 \\
\hline \multicolumn{3}{|l|}{$\mathrm{HH}$ head Age in years } \\
\hline $14-32$ & 625 & 25.1 \\
\hline $33-44$ & 658 & 26.4 \\
\hline $45-56$ & 630 & 25.3 \\
\hline $57-96$ & 581 & 23.3 \\
\hline \multicolumn{3}{|l|}{ HH head marital status } \\
\hline Cohabit $^{a}$ & 1950 & 78.2 \\
\hline Not cohabit ${ }^{\mathrm{b}}$ & 544 & 21.8 \\
\hline \multicolumn{3}{|l|}{ Wealth status } \\
\hline Low income & 346 & 14.9 \\
\hline Middle income & 913 & 39.3 \\
\hline Better income & 1063 & 45.8 \\
\hline \multicolumn{3}{|l|}{ Place of residence } \\
\hline Rural & 2493 & 99.9 \\
\hline Urban & 2 & 0.1 \\
\hline \multicolumn{3}{|c|}{ Farming main occupation of head } \\
\hline Yes & 2112 & 84.6 \\
\hline $\mathrm{No}^{\mathrm{c}}$ & 383 & 15.4 \\
\hline
\end{tabular}

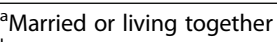

${ }^{\mathrm{b}}$ Single, divorced, separated or widowed

'student, Employee, shepherd, house worker; Private, merchant, unemployed, retired, disabled, housewife

$1.19,2.04)$ more likely to have ITNs as compared to those who didn't have any of the possible information sources (Table 4).

\section{Discussion}

This study examined ownership and utilization of ITN that enables us to compare with the national target in Ethiopia. It has been identified that housing access to some sources of information as well as maximum higher
Table 3 Ownership and utilization of ITNs among household at malarious areas of Dabat HDSS site, northwest Ethiopia, Oct. to Dec. 2014

\begin{tabular}{lll}
\hline Characteristics & Frequency & Percent \\
\hline ITN ownership & 394 & 15.8 \\
Yes & 2101 & 84.2 \\
No & & \\
Utilization of ITNs last night & 274 & 69.5 \\
Yes & 120 & 30.5 \\
No & & \\
Priority to sleep under ITN & 240 & 87.6 \\
All equal & 65 & 23.7 \\
Pregnant women & 86 & 31.4 \\
Child & 26 & 9.5 \\
Aged person & 40 & 14.6 \\
Others & a
\end{tabular}

ahusband \& wife, mother \& child, myself, patient, women

educational status attainment in HHs contribute to ITN ownership at the malarious areas of Dabat HDSS site.

According to the result of this study the proportion of ITN ownership is low, which remained too far from the 2015 national target of universal coverage. That is, less than one-fifth of the studied $\mathrm{HHs}$ at malarious areas had at least one ITN with two fold of the expected persons per ITN. It has been noted that HHs in Ethiopia are unevenly distributed at various altitudes within many districts and kebeles [31]. However, it has been observed that a large percentage of ITN ownership was found at malaria free areas of the Dabat HDSS site. This shows that ITN distribution might not consider altitude to prioritize $\mathrm{HHs}$ at malarious areas of the site. It may also show us wastage of resources in that there is unnecessary distribution of ITNs to those who did not deserve to have. Such kind of distribution of ITNs could be due to common barriers to delivery including cost, stockouts and poor logistics [32]. The distribution of ITNs should better be accompanied by tailored intervention strategy stratified by altitude [33].

Ownership of ITN at malarious areas of the Dabat DHSS seems lower than that of most study results in Ethiopia and elsewhere. For instance, reports show $81.7 \%$ in Itang [22], $49.8 \%$ in southern Nigeria [34], $65.5 \%$ in Kersa [20], 62.4\% in Gursum [18], and $58.8 \%$ in Arbaminch Zuria [15]. This may be due to a low distribution and/or retention of nets at the malarious areas of Dabat HDSS, northwest Ethiopia. However, nearly threequarters of the ITN owner HHs used at least one of their ITNs in the night preceding the survey, showing the utilization of ITNs in the study site is promising as far as the 2015 national target of $80 \%$ utilization. A similar study in southern Nigeria indicates a $75.4 \%$ utilization 
Table 4 Multivariable analysis for determinants of ownership of ITN at malarious areas at Dabat HDSS site, northwest Ethiopia, Oct. to Dec. 2014

\begin{tabular}{|c|c|c|c|c|}
\hline \multirow[t]{2}{*}{ Variables } & \multicolumn{2}{|c|}{ ITN ownership } & \multirow[t]{2}{*}{ COR $[95 \% \mathrm{Cl}]$} & \multirow[t]{2}{*}{ AOR $[95 \% \mathrm{CI}]$} \\
\hline & Yes & No & & \\
\hline \multicolumn{5}{|l|}{ Access to info source } \\
\hline Yes & $97(22.5 \%)$ & $335(77.5 \%)$ & $1.72[1.33,2.23]$ & $1.54[1.19,2.04]$ \\
\hline No & 297(14.4\%) & 1766(85.6\%) & 1 & 1 \\
\hline \multicolumn{5}{|c|}{ HH max. Educational status } \\
\hline Un educated & $117(13.5 \%)$ & $749(86.5 \%)$ & 1 & 1 \\
\hline primary & $226(16.2 \%)$ & 1165(83.8\%) & $1.24[0.98,1.58]$ & $1.19[0.92,1.55]$ \\
\hline secondary and above & $51(21.4 \%)$ & 187(78.6\%) & $1.74[1.21,2.52]$ & $1.60[1.08,2.35]$ \\
\hline \multicolumn{5}{|l|}{ HH family size } \\
\hline $1-4$ & $151(14.6 \%)$ & $883(85.4 \%)$ & 1 & 1 \\
\hline $5+$ & $243(16.6 \%)$ & 1218(83.4\%) & $1.17[0.94,1.45]$ & $1.10[0.85,1.42]$ \\
\hline \multicolumn{5}{|l|}{ HH head Age(years) } \\
\hline $14-32$ & 107(17.1\%) & $518(82.9 \%)$ & 1 & 1 \\
\hline $33-44$ & 119(18.1\%) & 539(81.9\%) & $1.07[0.80,1.42]$ & $1.02[0.74,1.40]$ \\
\hline $45-56$ & $88(14.0 \%)$ & $542(86.0 \%)$ & $0.79[0.58,1.07]$ & $0.72[0.51,1.00]$ \\
\hline $57-96$ & $80(13.8 \%)$ & $501(86.2 \%)$ & $0.77[0.56,1.06]$ & $0.78[0.57,1.08]$ \\
\hline
\end{tabular}

[34]. Another study in Itang, Gambella Region, Ethiopia, also shows a lower proportion of HHs (52.3\%) used ITNs in the night preceding the survey [22]. However, small proportion of $\mathrm{HH}$ at malarrious areas of Dabat HDSS site prioritize vulnerable groups including pregnant women and under five children to sleep under ITN. In distributing ITNs, educating $\mathrm{HHs}$ to prioritize pregnant and under five children to sleep under ITN should be considered [33].

A $\mathrm{HH}$ with some source of information, including radio receivers or mobile phones are more likely to have ITNs. This may be due to HHs with respondents that knew the cause of malaria, and have heard about ITN are more likely to own ITNs than their counterparts [18]. A related study in central Ethiopia consistently shows that housing access to some source of information contributes to the ownership of ITN [33]. Here, the Government needs to consider ITN promotion strategies targeting HHs with no access of information [33].

Households with a maximum educational status (secondary and above) are more likely to have ITNs as compared to those with completely uneducated members in the HHs. This may imply, the existence of a member with advanced educational status would lead the $\mathrm{HH}$ to be keen enough to collect their share from the health posts and avail themselves of the dates and places of distribution. It may also imply that collected ITNs in HHs with a better educated member would not wear out fast and get lost because of improper handling. This is attributable to knowledge about the sources of ITN, and belief that ITN does not protect or is not important to prevent malaria [35]. Consistently, some studies show participants with higher educational status improves ownership of ITN $[28,36]$. This is due to the fact that those with higher educational level may have knowledge about ITNs, malaria transmission, and mosquitoes in their school stay tending them to acquire the ITN $[28,36]$. In contrast, another study shows that HHs with no formal education own ITN above 35-fold more compared to those with formal education [35]. This difference could be attributable to the presence of a highly educated $\mathrm{HH}$ member capable of fostering ownership of ITN, no matter how un educated the head is.

As a limitation this work did not consider the rainfall and could not identify why ownership of ITN is greater at very high altitudes where malaria transmission is very rare. Further, this analysis was unable to establish causality due to cross sectional nature of the design and use of logistic regression. More factors including number of beds, draining/refilling of mosquito breeding sites, presence of rivers or streams, distance from rivers or streams, distance from health services, and access of vehicle transportation that could affect ownership of ITN were not included. So, the results should be considered with this limitations in mind.

\section{Conclusion}

In this study, the rural $\mathrm{HH}$ at malarious areas did not own sufficient ITNs, whereas overall utilization was promising. Moreover, prioritizing vulnerable groups (children and pregnant women) to sleep under ITN remains a public 
health concern in the study area. Programmers, partners, and implementers should consider tailored intervention strategy stratified by altitude in distributing ITN to achieve malaria eradication in the country. Additionally, ITN distribution should be accompanied by using exhaustive promotion strategies that consider people without access to any source of information, and educating $\mathrm{HHs}$ to prioritize key population (pregnant and under five children) to sleep under ITN.

\section{Abbreviations}

AOR: Adjusted odds ratio; COR: Crude odds ratio; GPS: Global Positioning System; HDSS: Health and demographic surveillance system; HH: Household; HHs: Households; HRS: Household registration system; INDEPTH: International Network of Demographic Evaluation of Populations and Their Health; ITN: Insecticide treated net; ITNs: Insecticide treated nets; Masl: Meters above sea level; OR: Odd ratio; PCA: Principal Component Analysis; S.D.: standard deviation; TV: Television; VA: Verbal autopsy

\section{Acknowledgments}

The authors are grateful to the University of Gondar for technical and financial support. We are also thankful to the people living in Dabat district, interviewed families, data collectors, and data management staff of the Dabat HDSS.

\section{Funding}

The study was supported by the Centers for Disease Control and Prevention (CDC) through Ethiopian Public Health Association (EPHA) in accordance with the EPHA-CDC Cooperative Agreement No. NU22GGH001039-04-00 and Gondor University. However, the findings and conclusion in this study are those of the author(s) and do not necessarily represent the official position of the supporters.

\section{Availability of data and materials}

The dataset used could be obtained upon reasonable request from the correspondence.

\section{Author's contributions}

All authors have substantial contributions. KA, AT, SMA, MY, TA and GAB conceived and designed the study, and coordinated data collection. KFM, ATT analyzed and interpreted the data. KFM, KA drafted, critically reviewed and edited the manuscript. AT and GAB critically reviewed and edited the manuscript. All authors read and approved the final manuscript.

\section{Ethics approval and consent to participate}

The Dabat HDSS site has obtained ethical clearance from the Health Research Ethics Review Committee (HRERC) of the University of Gondar, the Ethiopian Science and Technology Agency, the Ethiopian Public Health Association (EPHA), the US Center for Disease Control and Prevention (CDC). Informed consent was obtained from the head of the family or other eligible adult in the family in case when head is absent.

\section{Consent for publication}

Not applicable.

\section{Competing interests}

The authors declare that they have no competing interests.

\section{Publisher's Note}

Springer Nature remains neutral with regard to jurisdictional claims in published maps and institutional affiliations.

\section{Author details}

'Department of Epidemiology and Biostatistics, Institute of Public Health, College of Medicine and Health Sciences, University of Gondar, Gondar, Ethiopia. ${ }^{2}$ Departement of Human Nutrition, Institute of Public Health, College of Medicine and Health Sciences, University of Gondar, Gondar, Ethiopia. ${ }^{3}$ Departement of Health Service Management and Economics, Institute of Public Health, College of Medicine and Health Sciences,
University of Gondar, Gondar, Ethiopia. ${ }^{4}$ Dabat Research Centre Health and Demographic Surveillance System, Institute of Public Health, College of Medicine and Health Sciences, University of Gondar, Gondar, Ethiopia.

Received: 26 May 2017 Accepted: 12 November 2017

Published online: 21 November 2017

\section{References}

1. WHO. World malaria report 2015. Geneva: WHO; 2015.

2. Deribew A, Tessema GA, Deribe K, Melaku YA, Lakew Y, Amare AT, et al. Trends, causes, and risk factors of mortality among children under 5 in Ethiopia, 1990-2013: findings from the global burden of disease study 2013. Popul Health Metr. 2016;14:42.

3. World Health Organization. World malaria report 2014. Geneva: World Health Organization.

4. Federal Democratic Republic of Ethiopia Ministry of Health. National Five Year Strategic Plan for malaria prevention, control, and elimination in Ethiopia: 2011-2015. Addis Ababa: FMOH; 2011. p. 1-79.

5. Federal Ministry of Health. Guideline for malaria epidemic prevention and control in Ethiopia. Second ed. Addis Ababa: FMOH; 2004.

6. Ethiopian Federal Ministry of Health. Malaria program performance review 2013. Addis Ababa: FMOH; 2013

7. Federal Democratic Republic of Ethiopia Ministry of Health. National Five Year Strategic Plan for malaria prevention and control in Ethiopia: 2006-2010. Addis Ababa: $\mathrm{FMOH} ; 2006$.

8. Ethiopian Federal Ministry of Health, Ethioian Public Health Institute. Ethiopian Malaria Indicator Survey 2015. Addis Ababa: FMOH; 2013.

9. WHO. World malaria report: regional and country profiles 2015. Geneva: WHO; 2015.

10. Lengeler $C$. Insecticide-treated bed nets and curtains for preventing malaria. Cochrane Database of Systematic Reviews. 2004(2). doi: 10.1002/14651858. CD000363.pub2.

11. Global Strategic Plan. Roll Back Malaria 2005-2015. Geneva: Roll Back Malaria Partnership, WHO; 2005.

12. Macintyre K, Keating J, Okbaldt YB, Zerom M, Sosler S, Ghebremeskel T, et al. Rolling out insecticide treated nets in Eritrea: examining the determinants of possession and use in malarious zones during the rainy season. Tropical Med Int Health. 2006;11(6):824-33.

13. Organization WH. World malaria report 2011. 2011. Geneva: World Health Organization Google Scholar; 2012.

14. Flaxman AD, Fullman N, Otten Jr. MW, Menon M, Cibulskis RE, Ng M, et al. Rapid Scaling Up of Insecticide-Treated Bed Net Coverage in Africa and Its Relationship with Development Assistance for Health: A Systematic Synthesis of Supply, Distribution, and Household Survey Data. PLoS Medicine. 2010;7(8).

15. Astatkie A, Feleke A. Utilization of insecticide treated nets in Arbaminch town and the malarious villages of Arbaminch Zuria District, Southern Ethiopia. Ethiop J Health Dev. 2009;23

16. Ankomah A, Adebayo SB, Arogundade ED, Anyanti J, Nwokolo E, Ladipo O, et al. Determinants of insecticide-treated net ownership and utilization among pregnant women in Nigeria. BMC Public Health. 2012;12(1):1.

17. Baume $C$, Reithinger $R$, Woldehanna $S$. Factors associated with use and non-use of mosquito nets owned in Oromia and Amhara regional states. Ethiopia Malar J. 2009:8

18. Biadgilign S, Reda A, Kedir H. Determinants of ownership and utilization of insecticide-treated bed nets for malaria control in eastern Ethiopia. J Trop Med. 2012;2012

19. Deressa W, Fentie G, Girma S, Reithinger R. Ownership and use of insecticide-treated nets in Oromia and Amhara regional states of Ethiopia two years after a nation wide campaign. Trop Health Int Health. 2011;16

20. Gobena T, Berhane Y, Worku A. Low long-lasting insecticide nets (LLINs) use among household members for protection against mosquito bite in kersa. Eastern Ethiopia. BMC Public Health. 2012;12

21. Sena LD, Deressa WA, Ali AA. Predictors of long-lasting insecticide-treated bed net ownership and utilization: evidence from community-based crosssectional comparative study, Southwest Ethiopia. Malar J 2013;12(1):1.

22. Watiro AH, Awoke W. Insecticide-treated net ownership and utilization and factors that influence their use in Itang, Gambella region, Ethiopia: crosssectional study. Risk Manag Healthc Policy 2016;9:101. 
23. Bekele D, Belayhun Y, Petros B, Deressa W. Assessment of the effect of insecticide-treated nets and indoor residual spraying for malaria control in three rural kebeles of Adami Tulu District, south centeral Ethiopia. Malar J. 2012;11

24. Bennett A, Smith SJ, Jambai A, Alemu W, Kabano A, Eisele T. Household possession and use of insecticide-treated mosquito nets in Sierra Leone 6 months after a national mass-distribution campaign. PLoS One. 2012;7

25. Dagne G, Deressa W. Knowledge and utilization of insecticide treated mosquito nets among freely supplied household in Wonago Woreda, Southern Ethiopia. Ethiop J Health Dev. 2008;22

26. Legesse $Y$, Tegegn A, Belachew T. Ownership and use of treated bed nets in urban communities of assosa zone. Western Ethiopia Ethiop J Health Sci. 2008;17

27. Woyessa A, Deressa W, Ali A, Lindtjorn B. Malaria risk factors in Butajira area, south-central Ethiopia: a multilevel analysis. Malar J. 2013;12

28. Teklemariam Z, Awoke A, Dessie Y, Weldegebreal F. Ownership and utilization of insecticide-treated nets (ITNs) for malaria control in Harari National Regional State, eastern Ethiopia. Pan Afr Med J. 2015;21:52.

29. University of Gondar. Profile of Dabat Health and Demographic Surveillance System/Dabat Research Center. Gondar: University of Gondar; 2012.

30. WHO. International statistical classification of diseases and related health problems 10th revision (ICD-10) version for 2010. 2010.

31. President's malaria initiative in Ethiopia: Malaria operational plan FY 2014. Available from: https://www.pmi.gov/docs/default-source/defaultdocument-library/malaria-operationalplans/fy14/ethiopia_mop_fy14. pdf?sfvrsn=14.

32. Willey BA, Paintain LS, Mangham L, Car J, Schellenberg JA. Strategies for delivering insecticide-treated nets at scale for malaria control: a systematic review. Bull World Health Organ. 2012;90(9):672-84E.

33. Hailu A, Lindtjorn B, Deressa W, Gari T, Loha E, Robberstad B. Equity in longlasting insecticidal nets and indoor residual spraying for malaria prevention in a rural south Central Ethiopia. Malar J. 2016;15:366.

34. Johnson O, Inyang A, Etuknwa U, Udo U, Ubom I, Tommy D, et al. Awareness, ownership and utilization of insecticide treated nets among households in a rural Community in Southern Nigeria. Scholars J Appl Med Sci. 2015:3(2A):608-13.

35. Woyessa A, Deressa W, Ali A, Lindtjorn B. Ownership and use of long-lasting insecticidal nets for malaria prevention in Butajira area, south-central Ethiopia: complex samples data analysis. BMC Public Health. 2014;14:99.

36. Atieli HE, Zhou G, Afrane Y, Lee M-C, Mwanzo I, Githeko AK, et al. Insecticide-treated net (ITN) ownership, usage, and malaria transmission in the highlands of western Kenya. Parasit Vectors. 2011;4:113.

\section{Submit your next manuscript to BioMed Central and we will help you at every step:}

- We accept pre-submission inquiries

- Our selector tool helps you to find the most relevant journal

- We provide round the clock customer support

- Convenient online submission

- Thorough peer review

- Inclusion in PubMed and all major indexing services

- Maximum visibility for your research

Submit your manuscript at www.biomedcentral.com/submit 